\title{
Teorías geográficas, técnicas cartográficas y diplomacia: Hans Steffen, un geógrafo prusiano en los Andes Australes
}

\author{
Geographical theories, cartographic techniques and diplomacy. Hans Steffen, \\ Prussian geographer in the Chilean Andes
}

\section{Carla Lois \\ carlalois054@gmail.com \\ Centro de Estudios Históricos-Universidad Bernardo O'Higgins, Chile CONICET - Universidad de Buenos Aires, Argentina}

Recepción: 15 Julio 2020

Aprobación: 16 Septiembre 2020

Publicación: 02 Noviembre 2020

Cita sugerida: Lois, C. (2020). Teorías geográficas, técnicas cartográficas y diplomacia: Hans Steffen, un geógrafo prusiano en los Andes Australes. Geograficando, 16(2), e084. https:// doi.org/10.24215/2346898Xe084
Resumen: Hans Steffen, un destacado geógrafo prusiano (1865-1936) fue contratado por el Gobierno de Chile en 1889 como profesor de geografía para trabajar en el por entonces recientemente formado Instituto Pedagógico. A finales del siglo XIX, cuando Steffen ya había consolidado su posición profesional en Santiago, Chile y Argentina decidieron someter el litigio limítrofe sobre los Andes a un arbitraje internacional. En ese contexto, Steffen se involucró activamente en la preparación del documento que el gobierno chileno llevaría al diferendum. Esta presentación analiza las ideas, las teorías y las prácticas geográficas desarrolladas por Steffen para la conceptualización y la demarcación de la frontera entre Argentina y Chile a partir de los textos que produjo (diarios, libros didácticos, declaraciones diplomáticas, conferencias publicadas), las imágenes (mapas, fotos, bocetos, esquemas y notas de campo).

Palabras clave: Steffen, Diplomacia, Mapas, Andes, Chile.

Abstract: Hans Steffen, a prominent Prussian geographer (1865-1936), was hired in 1889 by the Government of Chile as Professor of Geography for the recently formed Pedagogical Institute, with the aim of educating Geography teachers and writing texts to contribute to the institutionalization of national geography. Towards the end of the nineteenth century, when Steffen was already an established professional in Santiago, Chile and Argentina submitted their Andean border litigation to international arbitration. In that context, Steffen was actively involved in preparing the document which the Chilean government would present at the dispute. This article analyzes the geographical practices, ideas, and theories developed by Steffen for the conceptualization and demarcation of the border between Argentina and Chile, by examining the texts (newspapers, didactic books, diplomatic declarations, published conferences) and images (maps, photos, sketches, outlines and field notes) he produced.

Keywords: Steffen, Diplomacy, Maps, Andes, Chile. 


\title{
1. INTRODUCCIÓN
}

\author{
Entre tu pueblo y mi pueblo \\ hay un punto y una raya. La \\ raya dice no hay paso, el \\ punto, via cerrada. (...) \\ Porque esas cosas no existen \\ sino que fueron trazadas \\ estén siempre separadas. para \\ que mi hambre y la tuya \\ Fuente: "Punto y raya", Aníbal Nazoa
}

\section{Hans Steffen, uno de los científicos emigrados: de Alemania a Argentina, del aula al terreno}

A principios de 1880, en Chile, preocupaba la inexistencia de una institución de educación superior encargada de preparar a los profesores secundarios. Por entonces, los profesores secundarios no recibían una formación pedagógica específica; por lo tanto, quienes desempeñaban dichas funciones transmitían contenidos vinculados a sus saberes, a su experiencia personal y los conocimientos adquiridos en sus respectivas profesiones o actividades, casi de oficio. A los efectos de subsanar este asunto, el gobierno del presidente Santa María decidió enviar una misión pedagógica a Berlín, integrada por Valentín Letelier, Claudio Matte y José Abelardo Núñez, para conocer con más detalle las prestigiosas teorías pedagógicas que estaban se desarrollando en Alemania (Pozo Ruiz, 2005).

En 1885, bajo el impulso decidido del educador José Abelardo Núñez, llegó a Chile un contingente de alrededor de 180 maestros alemanes, quienes en buena parte se dedicaron a enseñar y dirigir las escuelas normales. ${ }^{1}$ Era una experiencia que ya se había ensayado en la región: en la Argentina, se había fundado la Escuela Normal de Paraná, ${ }^{2}$ por iniciativa del presidente Domingo Faustino Sarmiento. Para ello, se contrató a un grupo de dieciocho maestras norteamericanas formadas por Horace Mann, reconocido como el fundador de la educación norteamericana moderna, a quien Sarmiento había conocido durante su estadía en los Estados Unidos. El 13 de junio de 1870 se dictó el decreto de institución de la Escuela Normal de Paraná, que tendría como director al norteamericano G. A. Stearns. En el artículo primero de este documento fundacional se afirma que el designo de esta nueva institución es

formar maestros competentes para las escuelas comunes (...) para que los aspirantes al profesorado adquieran, no solamente un sistema de conocimiento apropiado a las necesidades de la educación común en la República, sino también el arte de enseñar y las aptitudes necesarias para ejercerlo (citado en Núñez, 2010: 285).

Por ese entonces, el ministro plenipotenciario de Chile en Berlín, Domingo Gana Cruz, ${ }^{3}$ quien había recibido instrucciones de buscar y contratar profesores alemanes con el propósito de instalar en Chile un instituto pedagógico secundario entró en contacto con un joven profesor prusiano: Hans Steffen. ${ }^{4}$ Así, el joven profesor Steffen llegó a Chile en 1889, con tan sólo 24 años (junto a otros distinguidos pedagogos alemanes; entre ellos, los doctores Hansen, Lenz, Schneider, Tafelmacher), para asumir funciones docentes en la cátedra de Historia y Geografía del recientemente formado Instituto Pedagógico (Donoso, 1936; Galdames, 1936).

Friedrich Emil Hans Steffen Hoffman había nacido en Fuerstenwerder, Uckermark, el 20 de julio de 1865. Estudió en el Gymnasium (Liceo) Emperatriz "Reina Augusta" en el distrito berlinés de Charlotemburgo durante nueve años. Además de la formación humanista que tuvo en su infancia aprendió a dominar varios idiomas (alemán, latín, griego, francés y hebreo), y recibió formación en materias tales como matemáticas, física, historia y geografía. Cuando egresó del gymnasium, Hans Steffen continuó sus estudios de historia en Universidad Real Friedrich Wilhelm de Berlín; en 1884 empezó a estudiar Geografía en la Universidad 
de Halle; en 1886 obtuvo su doctorado y también obtuvo el título de doctor en Filosofía. Gracias a su formación erudita, se le encargó la redacción de la parte geográfica de la Enciclopedia Alemana, ${ }^{5}$ aunque no pudo terminar la tarea que se le había encomendado porque debió hacer el servicio militar.

La llegada de Steffen a Chile coincidió con un momento álgido en la disputa geopolítica de más duración que se ha dado entre la Argentina y Chile: la demarcación del límite internacional en los Andes australes. Aunque las acciones y las prácticas de Steffen estuvieron fuertemente involucradas en el apoyo a las reivindicaciones chilenas, también fueron cruciales para la diplomacia argentina y, en general, para el conocimiento geográfico de la Patagonia. En otras palabras, como es de esperar, las políticas cartográficas de las fronteras de la Argentina no solo tuvieron como actores a las instituciones locales, sino también a otros actores internacionales que actuaron en simultáneo. En este trabajo se procurará echar luz sobre las prácticas y los saberes chilenos que han dialogado con las prácticas y los saberes que la Argentina, a su vez, puso en juego. ${ }^{6}$ Dado que este texto no es un estudio diplomático, evitaré deliberadamente juzgar la validez jurídica de los argumentos expuestos por los personajes involucrados.

El análisis de este caso pretende ser un aporte para otras investigaciones que también se interesaren en examinar la configuración de una red de actores científicos, políticos y editoriales, que dé cuenta de los itinerarios de circulación de ideas y prácticas sobre las teorías geográficas y los debates científicos vinculados con las necesidades de los estados modernos de trazar las líneas divisorias de sus respectivos territorios, hecho decisivo en la formación de los estados modernos de América latina.

\section{LOS ANDES: DE FRONTERA A LÍMITE}

Luego de las revoluciones independentistas, tanto Argentina como Chile acordaban que la Cordillera de los Andes sería el límite entre los territorios de ambos estados "nuevos". Ese consenso se apoyaba en el mutuo reconocimiento de que todos los documentos de todas las épocas "antiguos y modernos, públicos y privados" $^{7}$ (Argentine-Chilean Boundary, 1900, p. 432) habían referido uniformemente y sin discrepancias que la Cordillera de los Andes era la frontera este de Chile. ${ }^{9}$ Las alturas de la cordillera de las Andes servían con eficacia para separar los territorios "nuestros" de los de "ellos". 10

También la cordillera era elemento de referencia para la aplicación del principio diplomático fundamental en la definición de los territorios era aceptado por ambas partes: tanto la Argentina como Chile habían acordado en 1858 que sus respectivos territorios habían sido heredados bajo el principio de utis possidetis, es decir, el principio del derecho internacional que reconoce la soberanía de los estados recientemente formados sobre los territorios que controlaban las jurisdicciones prexistentes antes de sus respectivas independencias.

A finales del siglo XIX, la idea de límite fue resemantizada: lo que hasta ese momento había poder sido una zona "vaga" pasó a ser una representación "neta", inscrita tanto en el papel como en el terreno, con el objetivo de que la demarcación no estuviera sujeta a contestación de ninguno de los estados parte, que tienen esa frontera en común (Raffestin, 1980, pp. 150-151) ${ }^{11}$. Esa línea neta debía ser mapeable. Podemos hablar de la imposición de un "imperativo cartográfico", en tanto el mapa se volvió el instrumento clave para definir, delimitar y demarcar la frontera. En este contexto, si bien como principio jurídico parecía fácil de suscribir por los plenipotenciarios en las reuniones celebradas en los primeros años luego de la disolución del vínculo colonial con España en torno a 1810, el hecho de que los Andes fueran una cadena montañosa dificultaba pensar cómo debía ejecutarse el trazado de ese límite neto. La tarea de dar vigencia y legitimidad a documentos que habían sido pensados para establecer separaciones internas administrativas dentro de un mismo imperio fue uno de los escollos diplomáticos más persistente entre Chile y Argentina en el nuevo proceso de delimitación política de territorios de estados nacionales. En el caso de los Andes australes, incluso luego de haber firmado el Tratado de 1881, el Protocolo de 1893 y el Acuerdo de 1896, la Argentina y Chile no lograron acordar la demarcación efectiva de la línea que separaría sus respectivos territorios, y 
siguieron reclamando la rectificación del límite, ambos amparándose en sus propias interpretaciones de las letras jurídicas suscritas.

Entonces, ¿cómo trazar la línea? Acá empezaba el verdadero conflicto. Mientras que la Argentina pretendía que la línea se trazara siguiendo la línea de las más altas cumbres, Chile sugería que se dibujara siguiendo la línea que dividía las aguas según la vertiente pacífica y la atlántica. La Argentina promovía lo que llamaba "el criterio orográfico", y Chile, el "hidrográfico". No hace falta decir que cada uno de los países sostenía un criterio cuya aplicación se traduciría en una ganancia de superficie territorial para sí mismo en detrimento del otro.

En cierto sentido era un problema inesperado: se suponía que la línea de altas cumbres y la línea divisoria de aguas coincidirían. Friedrich Ratzel, quien acababa de publicar su célebre tratado teórico Politische Geographie (1897), había contemplado incluso lo siguiente: el caso en que en la "arquitectura del relieve la dirección de la partición no sea lo suficientemente clara, la línea divisoria de aguas viene al socorro, y el derecho internacional admite, en caso de duda, la frontera sobre cadenas montañosas deba ser definida de esa manera" (Ratzel, 1897, p. 356). Pero eso suponía que la línea de altas cumbres no fuera visible o reconocible (y no que fuera diferente) $)^{12}$.

\section{LAS TEORÍAS GEOGRÁFICAS, LA DISCUSIÓN TEÓRICA Y LA INTERPRETACIÓN DE LAS FUENTES HISTÓRICAS}

En agosto de 1891, el coronel Sir Thomas Hungerford Holdich ${ }^{13}$ dio una conferencia en la sección geográfica de la Royal Academy of Sciences en Londres sobre los criterios de demarcación de límites políticos en las colonias africanas (Holdich, H. 1891, 596-607). A pesar de reconocer la practicidad de utilizar criterios artificiales (como meridianos y paralelos, sobre todo en aquellas zonas poco exploradas por los europeos), se manifestó a favor de utilizar los ríos como accidentes naturales. Entre las ventajas que señalaba, se refirió a la estabilidad de los cursos de agua (algo discutible), pero, sobre todo, a la facilidad con la que pueden ser reconocidos por sus propios pobladores como criterio de territorialidad. No obstante, seguía manifestando ciertas reservas respecto de las teorías de las fronteras naturales, ya que estaba convencido de que

Los límites son el producto inevitable del avance de la civilización; son invenciones humanas no necesariamente respaldadas por las disposiciones de la naturaleza y, como tales, solo tienen un valor sólido siempre que puedan hacerse lo suficientemente fuertes y seguras para evitar su violación e infracción (Holdich, 1899).

Poco después, el coronel Holdich se anticiparía al problema que enfrentaba a la Argentina y a Chile: en marzo de 1892 el propio Holdich pronunció un discurso en la Royal Geographical Society al que dio por título "El uso de la Geografía Práctica, ilustrado por recientes operaciones de frontera" utilizando como ejemplo la dificultad de utilizar el mayor macizo del mundo, el Himalaya, para trazar el límite entre la India y el Tibet. Conocedor de los debates sobre límites que se estaban dando en Londres, en enero de 1892, el perito chileno Barros Arana escribió a su par, el perito Francisco Pascasio Moreno, ${ }^{14}$ instándolo a reconocer que los especialistas recomendaban el criterio del divortium aquarum porque así lo recomiendan los "buenos principios de la Geografía y del Derecho Internacional” (citado en Steffen, 1931, p. 18).

Así, Hans Steffen escribió un largo texto titulado "La divisoria de aguas", ${ }^{15}$ con la intención de fundamentar científicamente el criterio diplomático que proponía Chile. ${ }^{16} \mathrm{~A}$ fines del siglo XIX, el estudio teórico de la división de las aguas como elemento morfológico en la geografía física había sido acogido con particular atención por los geógrafos alemanes. El geógrafo alemán Barón Ferdinand Richthofen dedicó a esta materia un capítulo especial en su Guía para exploradores (Richthofen, 1886, 3)

Reconocía que existían "divisorias normales" en las que las cumbres máximas coincidían con la línea divisoria de aguas. Pero también demostró que algunos ríos que nacían en la parte oeste de la cordillera 
desembocaban en el Pacífico y viceversa. Su discípulo Dr. Philippson, quien participó en el documento presentado por la Legación Chilena ante el Tribunal Arbitral de Londres, continuó estas investigaciones (Steffen, 1931, pp. 11-12, IAI). Otro asunto no menor que Phillippson destacó -y que nunca fue discutido ni por especialistas chilenos ni por los argentinos- es que en una misma región pueden coincidir varios regímenes diferentes de líneas, tanto divisorias de aguas como de altas cumbres; ante esta situación, la propuesta de Steffen era adoptar el criterio más amplio de cuenca hidrográfica y, por tanto, insistir en la existencia de una vertiente pacífica y otra atlántica (Steffen, 1931).

Para sostener su posición, Steffen recurrió a la autoridad del geógrafo Lucien Gallois, quien se basó, a su vez, en el por entonces bien reconocido físico y geógrafo Philipe Buache. La propuesta de Buache, ampliamente aceptada en la época, sostenía la existencia de las cadenas montañosas continuas como articuladoras de un sistema orográfico global, una especie de charpante de cadenas montañosas que recorrían la superficie terrestre, tanto en las tierras emergidas como en los fondos oceánicos. Buache hizo pública su teoría en su "Essai de Géographie physique" (1752, luego publicado en las mémoires de l'Académie des Sciences de Paris: Annales de Géographie, tomo X, 1901) (Steffen 1931, p. 2). A pesar de que la teoría de Buache gozaba de cierto prestigio, Steffen se ocupó de destacar que el geógrafo francés Conrad Malte-Brun había calificado a la teoría de Buache como el resultado de una entusiasta imaginación, que lo había llevado a dibujar montañas que no existían en la naturaleza (comentado en Steffen, 1931).

Ante la multiplicidad de teorías divergentes e incluso contradictorias, que no lograban dirimir "científicamente" el conflicto limítrofe, empezaron a entrar en juego elementos tales como los antecedentes de exploración y de ocupación histórica. Esto derivó en la búsqueda de los orígenes de la exploración patagónica, especialmente en lo que concernía a los cursos de agua: se buscaba encontrar el antecedente de exploración y asentamiento más antiguo en el que pudiesen basar los respectivos reclamos. Hay que remarcar que Steffen tiene una producción prolífica sobre estas cuestiones: entre sus obras están "La polémica sobre la autenticidad de la biografía más antigua de Colón" (Steffen, 1892, pp. 119-150) y "Relaciones de Colón con Toscanelli"17.

En el caso de Chile, dado que el argumento se basaba en usar como argumentación la separación de las vertientes atlántica y pacífica de las cuencas hidrográficas, los expertos buscaron, previsiblemente, desacreditar aquellas afirmaciones que adscribían ciertos ríos a la cuenca atlántica basados en exploraciones del periodo colonial de las cuales los diplomáticos argentinos desprendían la conclusión. Steffen también participó de este debate. Concretamente, acusaba al perito Moreno de tergiversar deliberadamente las fuentes:

Todas estas consideraciones más o menos desacertadas se derivan del error cometido por [el geógrafo alemán J.G.] Kohl, al identificar el Puerto Leones con uno de los golfos de la península Valdez y por consiguiente el río Guadalquivir con el río Negro de las cartas modernas. (...) Menos disculpable que el error de Kohl, que no conocía los originales de las relaciones de Veedor y Mori, es el ensayo del conocido geógrafo y perito argentino en la cuestión de límites con Chile, D. Francisco P. Moreno, de utilizar ciertos puntos de la tradición sobre el viaje de los españoles de 1535 para comprobar que hubiera habido, aun en tiempos históricos, cambios fundamentales en el régimen hidrográfico de la Patagonia. (...) [Moreno] hizo estampar, pues, en el Alegato sometido al Árbitro inglés en la cuestión de límites, la declaración siguiente: 'En la expedición hecha al interior de la Patagonia los compañeros de Simón de Alcazaba, en 1535, encontraron un río grande que aparece haber sido el río Deseado. Este río, sin embargo, se secó más tarde completamente, y contenía solamente unos pequeños pozos, cuando fue visitado por el Dr. Moreno en 1876. (Steffen, 1928, pp. 21-22)

Según Steffen, la línea propuesta por los argentinos cortaba los afluentes del río Aysén y afirma que "no está subordinada a ningún rasgo dominante de la topografía de la región (Steffen, 1931, p. 24). 


\section{Estrategias del TRABAJO DE CAMPo SEgÚN LOS INTERESES DIPLOMÁticos}

Para no abandonar su trabajo en el Instituto Pedagógico y también para aprovechar las condiciones climáticas favorables, las expediciones eran realizadas en verano (lo que hace suponer que, todavía, el trabajo en el Instituto era su prioridad). Steffen organizaba el equipo con ayuda de compatriotas inmigrantes. Así, Hans Steffen y sus equipos de exploradores y científicos realizaron expediciones todos los veranos entre 1892 y 1899.

A partir de estos viajes se redactó el argumento chileno más importante, que consta de cuatro volúmenes de aproximadamente 1.700 páginas. Eran dos volúmenes suplementarios, cada uno de los cuales contaba con varios cientos de páginas y una extensa colección de mapas. Como resultado de sus expediciones, Steffen produjo alrededor de 1.300 fotografías del sur de la Patagonia y otras regiones de Chile, y 433 bocetos dibujados a mano de mapas, mediciones y/o trabajos, así como unos 70 manuscritos. Todos estos materiales fueron incorporados a dicho informe.

Si bien el principal objetivo de las expediciones había sido definir la configuración del sistema hidrográfico (curso, dirección e intensidad de los ríos), también sus expediciones trajeron un conjunto de informaciones climatológicas, geomorfológicas y botánicas que fueron entregadas al Museo Nacional de Santiago (fue una importante contribución a la conformación del acervo de los por entonces incipientes museos, ${ }^{18}$ hoy Museo de Historia Natural), que entonces dirigía el también germano Rudolf Philippi.

La logística de los itinerarios de las expediciones de Steffen siempre consistió en remontar los ríos hasta sus nacientes e incluso buscar conexiones entre diversos ríos, siempre que esto permitiera extender las fuentes hacia el oriente. El trabajo de campo de Steffen estuvo íntimamente comprometido con la demostración de la tesis chilena del aqua divortium. El hecho de que sus itinerarios hayan consistido en remontar ríos y en corregir la "cartografía argentina" es solo una parte de ello.

Además, durante sus viajes, Steffen bautizó importantes alturas y cordones montañosos (que luego serían contestados por el perito argentino). La cuestión del bautismo toponímico no es un tema menor: se ha insistido mucho en que "hay un paralelo innegable entre la escritura topográfica y el gesto de nominación del descubridor" y que "los nombres designan tomas de posesión, apropiaciones" (Schlögel, 2003, p. 223). La denominación toponímica era, de hecho, un modo de apropiación simbólica que serviría para reclamar la apropiación material. ${ }^{19}$ La diplomacia chilena sostuvo que a partir de ellos las expediciones lograron establecer fehacientemente el "divortium aquarum continental", tesis sustentada por Chile que invocaba el Tratado de Límites de 1881. Todas las expediciones traían datos que confirmaban la tesis chilena; podemos inferir que sus empatías políticas habían tomado la forma de prácticas científicas.

Previsiblemente, la estrategia argentina, por el contrario, consistía en recorrer y mapear los territorios de las estepas y las cordilleras: en un entorno mayoritariamente hostil desde el punto de vista de sus condiciones naturales para las actividades productivas, a mediados de la década de 1880, extensos sectores de tierra agrícola en el valle inferior del Chubut habían sido ocupados; se organizaban exploraciones para buscar nuevas tierras explotables (además, no se descartaba la idea de encontrar oro) ${ }^{20}$. Uno de esos viajes fue comandado por el gobernador del Territorio Nacional de Chubut, Luis Jorge Fontana; estuvo acompañado por un baqueano y por una treintena de jinetes que se internaron en el territorio chubutense entre octubre de 1885 y febrero de 1886. Como resultado de la expedición, realizaron una descripción geográfica y un mapa que fue presentado al presidente Julio Argentino Roca (Lois, 2014). La Argentina, a su vez, publicó Evidencia Argentina, una obra compuesta por cuatro volúmenes y un atlas. Los volúmenes compilan textos en los que esencialmente se desarrolla la argumentación diplomática de los reclamos argentinos y se refuta la posición chilena. A lo largo de las 1091 páginas que suman los cuatro volúmenes se reproducen 71 mapas, 182 fotos, 175 fotos panorámicas insertas en láminas plegadas, 12 grabados y 15 croquis. El documento Evidencia Argentina organiza toda su argumentación a partir de esta idea clásica de la Cordillera como límite y la 
reactualiza conceptualizándola como una frontera natural. ${ }^{21}$ En suma: las exploraciones realizadas por ambas partes estaban estructuradas a los fines de probar lo que querían probar. Podían estar fundamentadas sobre cimientos científicos e incluso prácticos, pero el criterio estructurador sobre el cual se definían las campañas, sus itinerarios, el tipo de observaciones y registros, era político.

Por eso, si bien las exploraciones eran un operativo científico, Steffen tenía claro que su misión se fue volviendo cada vez más de carácter político. En una conferencia dictada en 1897 en la Sociedad Científica Alemana de Santiago (Deutscher Wissenschaftlicher Verein zu Santiago), Steffen se disculpó por no poder dar a conocer los resultados de su último viaje a Aysén, puesto que primero debía enviar un informe al gobierno, luego de lo cual podía exponerlo públicamente: el conocimiento geográfico producido durante el trabajo de campo se volvió una cuestión de Estado.

Otra dimensión de las rivalidades políticas que atravesaban permanentemente todas las prácticas científicas la constituyen las innumerables tensiones entre los expertos argentinos y los chilenos. En una ocasión parte de su equipo fue arrestado por la policía argentina y sus instrumentos sustraídos. Solo los liberaron por la vía diplomática y luego de supuestos maltratos, por lo que cuando Francisco Moreno (el perito encargado de la investigación en Argentina) le ofreció que compartieran ambos resultados Steffen le dijo que no porque había motivos estratégicos de por medio. "Vortrag über die chilen. (1987) AisenExpedition, in Deutschen Verein, Santiago"., p. 1. [En: Legados Hans Steffen, Instituto Iberoamericano de Berlín; Caja B-1.]

\section{LOS MÉTODOS DE LAS EXPLORACIONES}

La primera tarea antes de encarar las expediciones consistía en encargar e importar instrumentos que, por entonces, eran complejos de conseguir: barómetro, hidrómetro, termómetro y cámara fotográfica (Figura 1). La segunda, reclutar a dos alemanes que conocieran la zona, principalmente de Valdivia o Chiloé (Martinic, 2005). A través de ellos conseguía a otros lugareños para que llevaran los equipos, y así formaban un grupo de cerca de diez personas. 


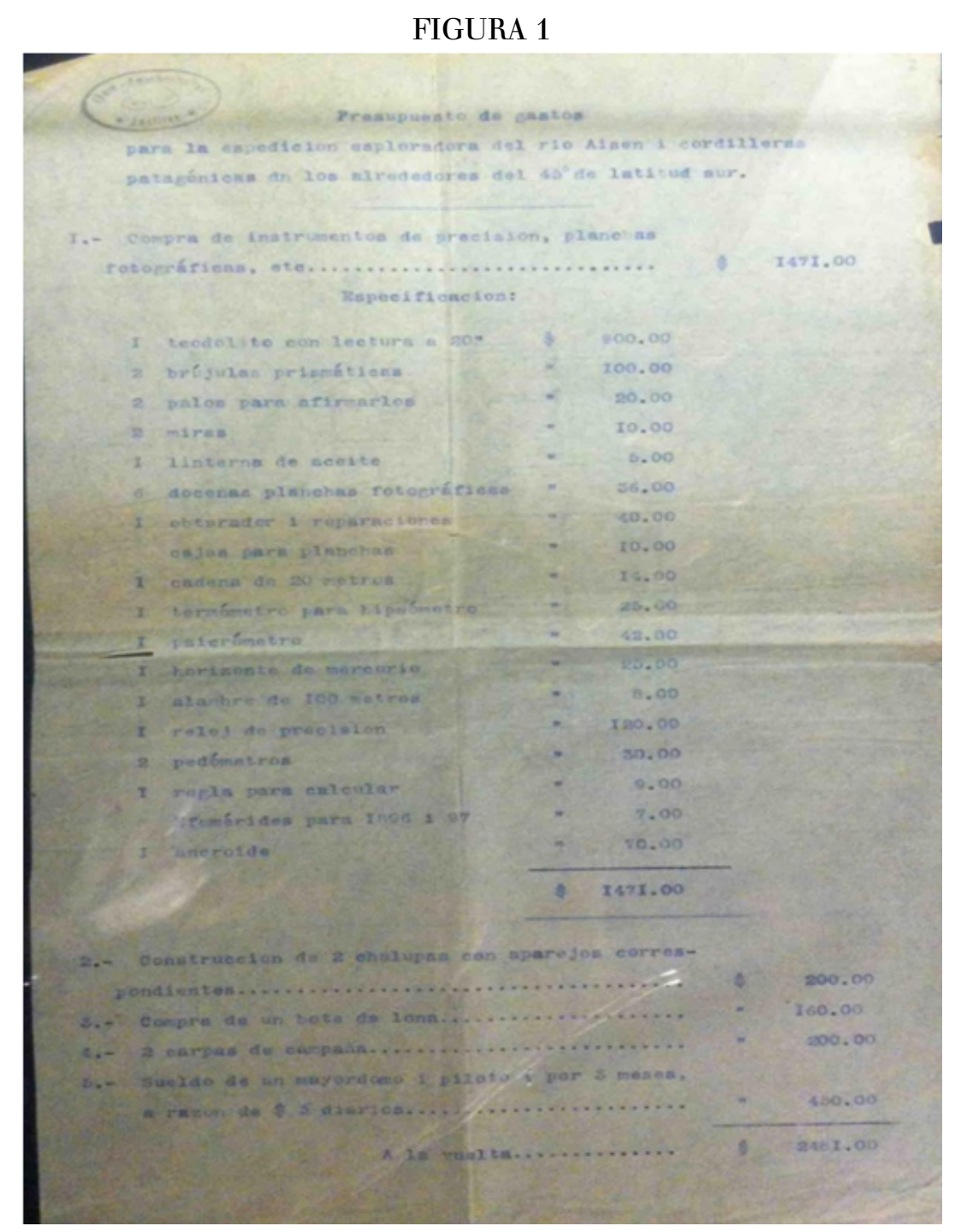

La lista de materiales y el presupuesto solicitado por Steffen para llevar a cabo la expedición en la que remontó el río Aysén (1896-1897) incluía: 1 Teodolito con lectura a 20", 2 brújulas prismáticas, 2 palos para afirmarlos, 2 miras, 1 linterna de aceite, 6 docenas planchas fotográficas, 1 obturador y caja de reparaciones, 1 cadena de 20 metros, 1 termómetro para hipsómetro, 1 cronómetro, 1 horizonte de mercurio, 1 alambre de 100 metros, 1 reloj de precisión, 2 pedómetros, 1 regla para calcular efemérides para 1896 y 1897, 1 aneiroide, Construcción de 2 chalupas con aparejos correspondientes, Compa de un bote de lona, 2 carpas de campaña, Sueldo para mayordomo y piloto por tres meses.

Fuente: fotografía propia en Exposición "Hans Steffen. Grenzerfahrungen eines deutschen Geografen” in Chile. Universität Hamburg, 2015.

Las exploraciones se hacían generalmente a pie, utilizando embarcaciones de madera y lona, que eran transportadas a hombro y también con balsas construidas por los propios expedicionarios en el lugar de partida de la expedición. Así se recorrieron centenares de kilómetros de zonas abruptas e inhóspitas, cruzando fiordos, ríos lagos y pantanos, montañas, glaciares y bosques impenetrables, donde las sendas se abrían a golpes de hacha y machete. Todo esto ocurría en medio de lluvias, nevadas, temporales, vientos huracanados y fríos helados e intensos, y con precarias condiciones de abrigo y alojamiento (Pozo Ruiz, 2005).

Steffen sistematizó el trabajo sobre la base de la elaboración de diarios de expedición, el Tagebuch (que podría traducirse como diario) eran libretas de pequeño formato, para asegurarse de que fueran fáciles de manejar, usar y transportar (Figura 2). 


\section{FIGURA 2}

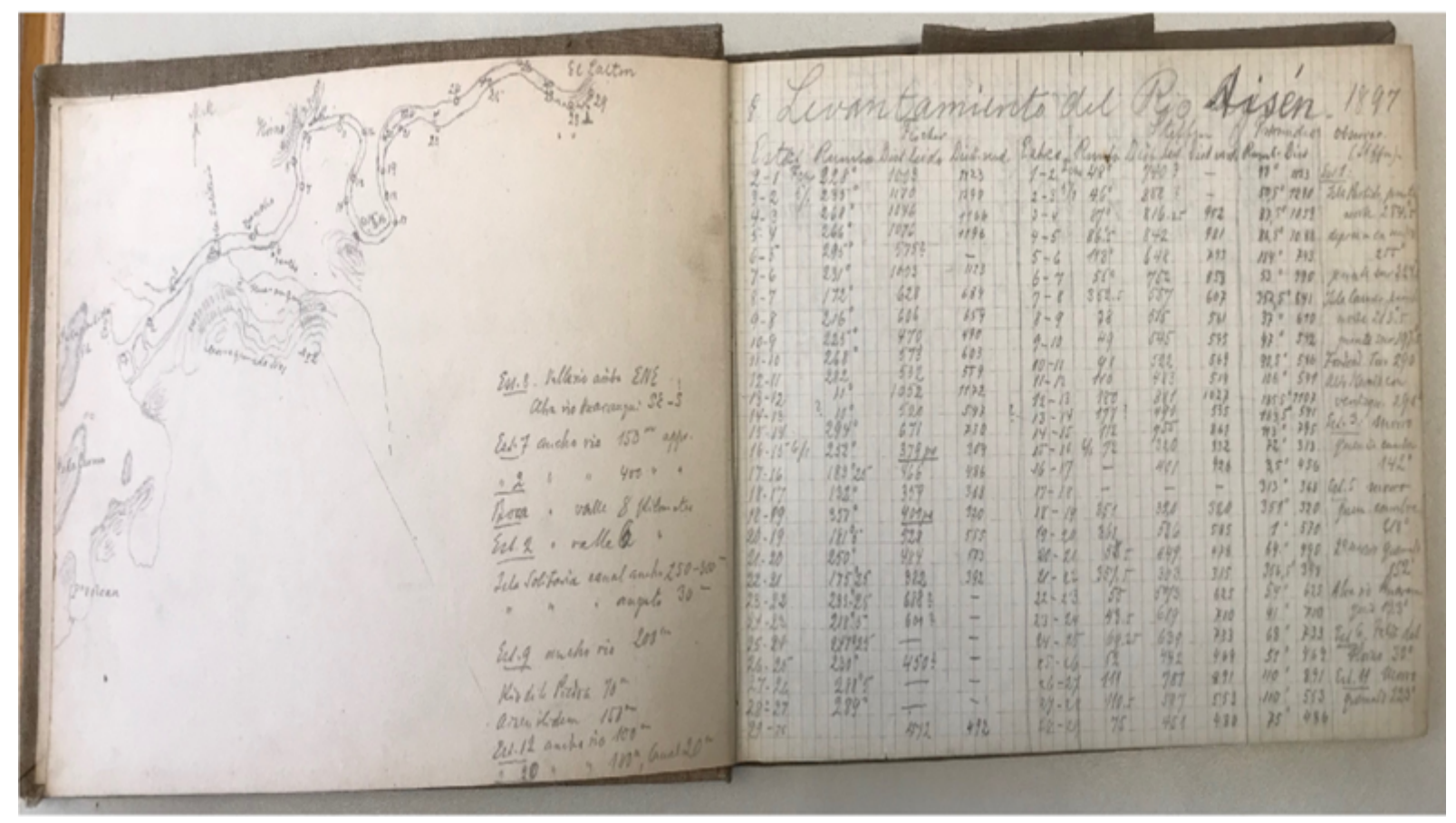

El Tagebuch solía ser un cuaderno con hojas cuadriculadas en las hojas (para las medidas) y hojas en blanco en las hojas impares (para bosquejos y otras anotaciones). En el "Rousenaufhahnmen am Rio Aysen und Rio Cisnes (1896-97 u. 1897-198)", Steffen ensayaba el diseño del curso de los ríos y tomaba notas ad hoc en la página par. En la página par seguía un protocolo de registros sistemáticamente organizado en un exhaustivo cuadro de doble entrada.

Fuente: Foto propia tomada en la Biblioteca del Leibniz-Institut für Länderkunde, Liezpieg Universitä, Liezpieg. Fondo Steffen.

Estas libretas no consistían en relatos de viajeros donde quedasen plasmadas las impresiones personales del lugar visitado, sino que tenían utilidades prácticas, tales como recopilar información y registrar el trabajo de campo.

Hans Steffen hizo un uso sistemático de procedimientos científicos e instrumentos modernos de asombrosa precisión. El método de viaje científico aprendido de su maestro Richthofen hizo que las exploraciones se organizaran a partir de las mediciones controladas in situ. Los diarios de Steffen, tal como lo recomendaba Richthofen, acumulaban todo tipo de registros: pluviométricos, de temperatura, de aire, hipsométricos y fotográficos entre otros, divididos por días y lugares, muchas veces complementados por bocetos, muchas veces, extremadamente sencillos, tal vez con algunos elementos mínimamente coloreados y señalados los lugares desde donde se habían tomado tales imágenes. Por otra parte, el Tagebuch servía para que, más tarde, se pudieran recordar los accidentes geográficos (las formas de las montañas, el curso de los ríos, entre otros) (Sanhueza Cerda, 2012), así como las relaciones espaciales entre los materiales recogidos y las observaciones en el terreno. Por tanto, se incluían numerosos bosquejos cartográficos y paisajísticos, algunos de los cuales, adicionalmente, servían para señalar las paradas de la expedición. Puede decirse que, en algunos de esos diseños a mano alzada, se hacía lo que en un trabajo anterior he dado en llamar "tratamiento cartográfico": ${ }^{22}$ sobre el boceto se marcan elementos típicamente cartográficos que habitualmente suelen ser omitidos en bocetos artísticos, los cuales privilegian lo estético por sobre la precisión de la observación.

Para la localización de los puntos en el mapa se usaban las anotaciones telemétricas, levantadas usando el sistema óptico, que permite apreciar y/o medir la distancia entre una cosa o un elemento geográfico y el punto de mira de un observador. También, con el auxilio de las cartas geográficas que llevaban al campo, en los bocetos también solían indicarse las coordenadas.

Los registros de las expediciones no quedaban solamente en los manuscritos Tagbücher, ya que la difusión de la información geográfica recogida de primera mano podía ser un indicador positivo del reconocimiento 
científico del terreno y, así, ser utilizado como precedente para la reivindicación de esos territorios: solían ser incluidos en los documentos diplomáticos o bien puestos en circulación como hojas sueltas. Finalmente, el conjunto de materiales permitía configurar mapas topográficos que se basaban en los lenguajes cartográficos de la época (Figura 3).

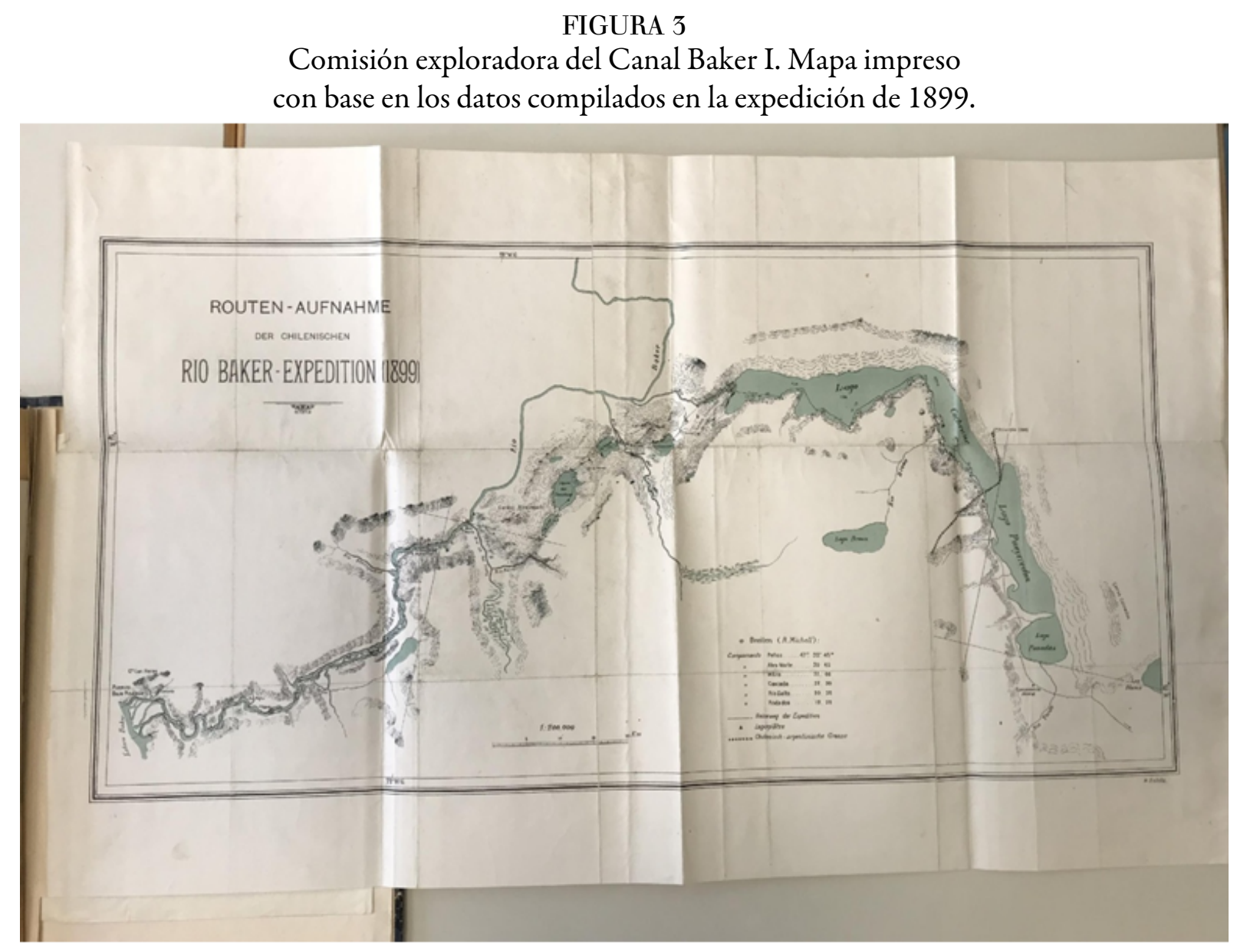

Fuente: Foto propia tomada en la Biblioteca del Leibniz-Institut für Länderkunde, Liezpieg Universität. Liezpieg. Fondo Steffen.

\section{UNA gEOGRAFíA DE LA PERSUASIÓN: EL EPISODIO LONDRES}

La amplia experiencia adquirida por Hans Steffen en sus sucesivas expediciones y su prestigio de explorador motivaron a las autoridades chilenas a contratar, mediante decreto de 11 de octubre de 1899 , sus servicios como consultor técnico de la Comisión Arbitral de Chile en Londres. Este acontecimiento vinculó nuevamente al profesor Steffen con Domingo Gana (cuyo gobierno contó con los servicios técnicos del destacado ingeniero chileno Alejandro Bertrand) ${ }^{23}$, quien, recordemos, algunos años atrás lo había invitado para enseñar en el Instituto Pedagógico, y que ahora era el ministro de Chile en Londres.

En sintonía con el interés por temática y los desafíos como los que planteaba este conflicto, tanto Hans Steffen como Francisco Moreno fueron invitados a la Royal Geographical Society para exponer sus puntos de vista respecto a las teorías geográficas aplicables a la demarcación de límites. Expresamente se les pidió que restringieran sus exposiciones a cuestiones científicas y no hicieran proselitismo. El propio Scott Keltie, por entonces director de la Real Sociedad Geográfica de Londres, le aseguraba a Steffen que: "Nuestro único interés es la geografía, y no deseamos preocuparnos por las preguntas de límites ni parecer favorecer a un lado más que al otro". 
Primero hizo su presentación Hans Steffen. Más tarde, aparentemente la discusión se tornó álgida y el debate viró hacia cuestiones sensibles, por lo que Steffen no dudó en reclamar al presidente de la RGS que no se había respetado lo pactado respecto de la politización del debate:

Dear Dr. Keltie

Las observaciones que el Coronel Church, quien según tengo entendido fue solicitado por la Sociedad para discutir mi documento, anoche en la reunión hizo algunas observaciones sobre el texto general y algunos puntos especiales de mi artículo que me obligan a expresarle que lamento no haber tenido la oportunidad de dar en la misma reunión una respuesta debida a las críticas de Coronel Church, tal como hubiera sido mi deseo. Al mismo tiempo, no puedo dejar de expresar mi sorpresa de que el Coronel Church se haya ocupado de discutir precisamente algunas partes del documento de mayo cuya lectura fue omitida por mí, satisfaciendo su deseo privado de evitar toda alusión, por indirecta que sea, a la cuestión de la frontera internacional, respecto de la cual la Sociedad no desea discutir. (Steffen, 20 de marzo, 1900)

Luego, el perito argentino Francisco Moreno contestó la presentación de Steffen y su disertación fue publicada en el Journal de la Royal Geographical Society. Allí desacreditaba todo lo afirmado por Hans Steffen y renombraba todos los accidentes geográficos referidos por Steffen.

\footnotetext{
Los mapas generales presentados en enero pasado al Ministerio de Relaciones Exteriores del Gobierno argentino para ilustrar las diferencias existentes entre los expertos argentinos y chilenos sobre la demarcación de límites, y sometidos al arbitraje del Gobierno de Su Majestad, estas y otras características geográficas de la Patagonia están representados, mientras que no están en los mapas de Chile. En febrero pasado, entregué a la Royal Geographical Society mapas generales y detallados de la Patagonia, que pueden usarse para publicar el que ilustra mi conferencia, y estos mapas contienen las mismas características y los nombres que se les dieron. (...)

Preparé esa parte del mapa 3 sobre los resultados de las investigaciones de mis asistentes y de mí mismo durante la exploración realizada en la vertiente oriental de la Cordillera de los Andes y de algunos de los fiordos de las laderas occidentales en 1897 y los primeros meses de 1898. El Dr. Steffen le dio al río el nombre de "canal Baker" hacia la entrada de Calen, el fiordo transversal más grande de la Patagonia occidental que (...) fue explorado por el vapor chiliano Yoro y por los vapores argentinos Azopardo y Gotondra en diciembre de 1897. Bajo mi dirección descubrimos un gran río, al que le di el nombre de Las Heras (río Baker del Sr. Steffen) (...). El río Las Heras (río Baker del Dr. Steffen) no es un río chileno en toda su extensión; Corta la Cordillera de los Andes. Creo que es necesario hacer estas explicaciones para evitar confusiones en la geografía de la Patagonia. (Moreno, F. ,1898-1899, p. 219-220).
}

En el último punto, al pasar, se menciona que el río Baker/Las Heras escurría tanto sobre territorio chileno como argentino. Esta cuestión y otras similares van a ser retomadas por el informe técnico que realiza una expedición a la región antes de que Su Majestad manifestara el resultado del arbitraje.

\section{El RESUltado DEL LAUdo y LAS REACCiOnes}

La sentencia del tribunal arbitral inglés no solo fue el resultado del análisis de los materiales aportados por ambas partes, sino que también se apoyó en el informe realizado por expertos ingleses durante los primeros meses de 1902 en una expedición a la zona fronteriza. La expedición fue encabezada por el inglés Thomas Holdich, acompañado por expertos chilenos y argentinos, entre ellos Hans Steffen y Francisco Moreno. Además de consideraciones teóricas, según Holdich, el problema principal era que todavía no había suficiente conocimiento geográfico de la región. La expedición de dos meses estuvo lejos de ser suficiente para obtener una imagen confiable del área geográfica ni de las condiciones en la región fronteriza. No obstante, los ingleses no estaban tan preocupados por el reconocimiento topográfico, sino que, más bien, buscaban comprobar la verosimilitud de los argumentos esbozados tanto por los argentinos como por los chilenos.

El informe técnico fue firmado por la comisión arbitral que estuvo compuesta por Magnaughten (lord de Apelaciones de ordinario y miembro del Muy Honorable Consejo Privado de V. M.), John C. Ardagh (mayor general y miembro del Consejo de la Real Sociedad Geográfica), T. Hungerford Holdich (coronel de Ingenieros Reales y vicepresidente de la Real Sociedad Geográfica) y E. H. Hills (mayor de Ingenieros Reales, jefe de la Sección Topográfica de la División de Informes. Secretario del Tribunal Arbitral). El informe 
técnico de la comisión también revela la modalidad de trabajo de la comisión arbitral. Me quiero permitir una cita extensa, porque ella reúne los aspectos principales llevados a cabo por la Comisión Técnica y permite para apreciar - más cabalmente que si fuera parafraseada- el tono, los puntos tenidos en cuenta y el orden en que fueron enunciados.

2. ${ }^{\circ}$ Hemos estudiado las copias de los tratados, convenciones, protocolos y documentos que han sido suministrados para uso del Tribunal por los ministros de las Repúblicas Argentina y de Chile en este país.

3..$^{\circ}$ Nos hemos reunido como Tribunal en el Ministerio de Relaciones Exteriores en varias ocasiones y hemos oído exposiciones y argumentos orales.

4..$^{\circ}$ Hemos invitado a los representantes de los respectivos Gobiernos a que nos suministraran la más amplia información sobre sus respectivas pretensiones, presentándonos mapas y detalles topográficos del territorio en litigio, y se nos ha suministrado datos y argumentos copiosos que agotan la materia, en muchos volúmenes impresos ilustrados, con mapas y planos y un gran número de fotografías que indican pictóricamente el aspecto topográfico del país.

5..$^{\circ}$ Deseamos aprovechar esta oportunidad para reconocer lo que debemos los representantes y peritos nombrados por ambos Gobiernos por sus laboriosas investigaciones, por los extensos relevamientos que han efectuado en regiones hasta ahora poco conocidas y por la información histórica y científica que nos han presentado relativa a la controversia (...).

6. Después de la consideración preliminar de esta voluminosa información, llegamos a un punto en que creímos conveniente que se hiciera un estudio real del terreno, como lo determina la Convención de 1896, y a insinuación nuestra, el Gobierno de Vuestra Majestad designó a uno de nuestros miembros, el Coronel Sir Thomas Holdich, del Cuerpo de Ingenieros Reales, Vicepresidente de la Real Sociedad Geográfica, para que se trasladara como Comisionado al territorio disputado, acompañado de una comisión experimentada.

7. ${ }^{\circ}$ Sir Thomas Holdich y sus oficiales fueron recibidos con gran cordialidad y amistosa deferencia por los Presidentes de las dos Repúblicas, y se les prestó toda clase de auxilio y de facilidades por los oficiales y peritos de ambos Gobiernos.

8. La Comisión técnica así nombrada, visitó todos los puntos accesibles del territorio en litigio, que ofrecían importancia para la solución de la cuestión, y adquirió una gran suma de información adicional sobre cuestiones que presentaban ciertas dificultades. Sus informes han sido presentados al Tribunal y la información que ellos contienen, complementaria, como lo es, de la suministrada por los respectivos representantes, es en nuestra opinión, suficiente para habilitarnos a formular nuestras recomendaciones.

10. El Gobierno Argentino sostenía que la línea que debía tenerse en vista, teñía que ser esencialmente una frontera orográfica, determinada por las más altas cumbres de la Cordillera de los Ancles; en tanto que el Gobierno Chileno sostenía que la definición contenida en el tratado y protocolos, sólo podía hacerse efectiva por una línea hidrográfica, que formara la división de las aguas entre los Océanos Atlántico y Pacífico, dejando para la Argentina las cuencas de todos los ríos que se derraman en el primero, dentro de la línea de costa argentina, y para Chile, las cuencas de todos los ríos que se derraman en el Pacífico, dentro de la línea de costa chilena.

11. Reconocimos desde el principio de nuestras investigaciones, que en abstracto, existía una diferencia cardinal entre estas dos teorías; un límite orográfico puede ser indeterminado, si las cumbres Individuales a través de las cuales pasa, no están plenamente especificadas, en tanto que una línea hidrográfica, desde el momento en que se indican las cuencas, admite delimitación en el terreno.

(...) 15. En una palabra, las líneas orográfica é hidrográfica son frecuentemente irreconciliables, y ni siquiera se conforman del todo con el espíritu de las convenciones que hemos sido llamados a interpretar. Se ha evidenciado por la investigación llevada a cabo por nuestra Comisión técnica, que los términos del tratado y protocolos son inaplicables a las condiciones geográficas del país a que se refieren. Unánimemente hemos considerado ambiguos los términos de las convenciones y susceptibles de las diversas y contrarias 
interpretaciones que de ellos han hecho los representantes de las dos Repúblicas. [Los destacados son propios. (Drago, L, 1903)]

El último punto fue crucial porque definía la imposibilidad de apoyar a cualquiera de los dos países, y, a su vez, anunciaba que el criterio sería configurado a partir de diversos elementos que no satisfarían completamente a ninguna de las partes.

El 20 de noviembre de 1902 se dio a conocer el laudo arbitral de su majestad británica Eduardo VII, que fijaba un límite ad hoc, una línea que a veces coincidía con la línea de altas cumbres y a veces coincidía con la divisoria de aguas (que respetaba, incluso, la autodeterminación de algunos asentamientos ya instalados, como fue el caso de Trevelin). Sobre la línea limítrofe debían establecerse más de 400 puntos medidos en el terreno. La superficie en disputa (alrededor de $90.000 \mathrm{~km} 2$ ) fue distribuida de manera tal que, al final de cuentas, cada una de las partes recibió sumas casi equivalentes: a Chile 54,000 km2 y a Argentina 40,000 $\mathrm{km} 2$ de la controvertida área fronteriza. La decisión causó insatisfacción en ambos lados, pero fue finalmente reconocida tanto por la Argentina como por Chile. Hans Steffen se quejó de la arbitrariedad de criterios que aplicó el tribunal británico y consideró que el juicio aplicado no solo perjudicaba a Chile en la cantidad de kilómetros cuadrados, sino en la calidad de los suelos de las regiones repartidas (Steffen, 1931, p. 33)

Una vez de regreso de Londres, en octubre de 1902, se abocó a redactar una respuesta a la breve réplica que la legación argentina entregara al Tribunal Arbitral en septiembre de dicho año. En un documento de 23 páginas, Steffen refutaba las aseveraciones de los especialistas argentinos e insistía en legitimar la tesis de que el límite pactado debía seguir el "divortium aquarum continental". 24

Concluido el diferendo limítrofe, el profesor Hans Steffen retomó sus actividades académicas en el Instituto Pedagógico y solo dos años después, en 1904, volvió a Europa aduciendo motivos de salud y se radicó en Suiza. Si se tiene en cuenta que falleció más de treinta años después, en 1936, sin haber vuelto a Chile, podríamos sugerir que, más que problemas de salud, habrían sido otros los motivos que lo llevaron a cruzar el Atlántico luego de tantos años de trabajo en Chile. Parece plausible pensar que se hubiera sentido profundamente decepcionado por la "inutilidad" de su trabajo una vez conocido el resultado del arbitraje británico. Incluso existe una leyenda, que me ha sido imposible corroborar, pero que sería sintomática de la frustración personal que sentía ante la falta de lo que él designa como la discrecionalidad del laudo en detrimento de los argumentos científicos: se cuenta que Steffen recibió las noticias del laudo mientras estaba haciendo triangulaciones trigonométricas con su equipo, y que, al notificarse, dijo: "Compañeros, levanten todo porque nos volvemos a Santiago: estamos trabajando en suelo argentino", 25 como si su tarea no tuviese sentido.

\section{Con las botas limpias: los ANDES COMO laboratorio PARA SU ESTUDio DESDE LOS CENTROS DE CÁLCULO}

Poco se ha indagado más allá de su participación activa en la academia y en la diplomacia chilena. Sin embargo, Steffen ha realizado un prolífico trabajo durante las casi tres décadas que vivió en Suiza a la vuelta de su estancia en Chile. Por un lado, de regreso en Europa, retomó su cooperación con la enciclopedia alemana. Por el otro, bastante tiempo después de haberse dirimido el asunto diplomático en Chile, siguió investigando sobre el tema. Entre sus papeles he encontrado el atlas personal (Figura 4) que elaboró como síntesis de su experiencia patagónica. 


\section{FIGURA 4}

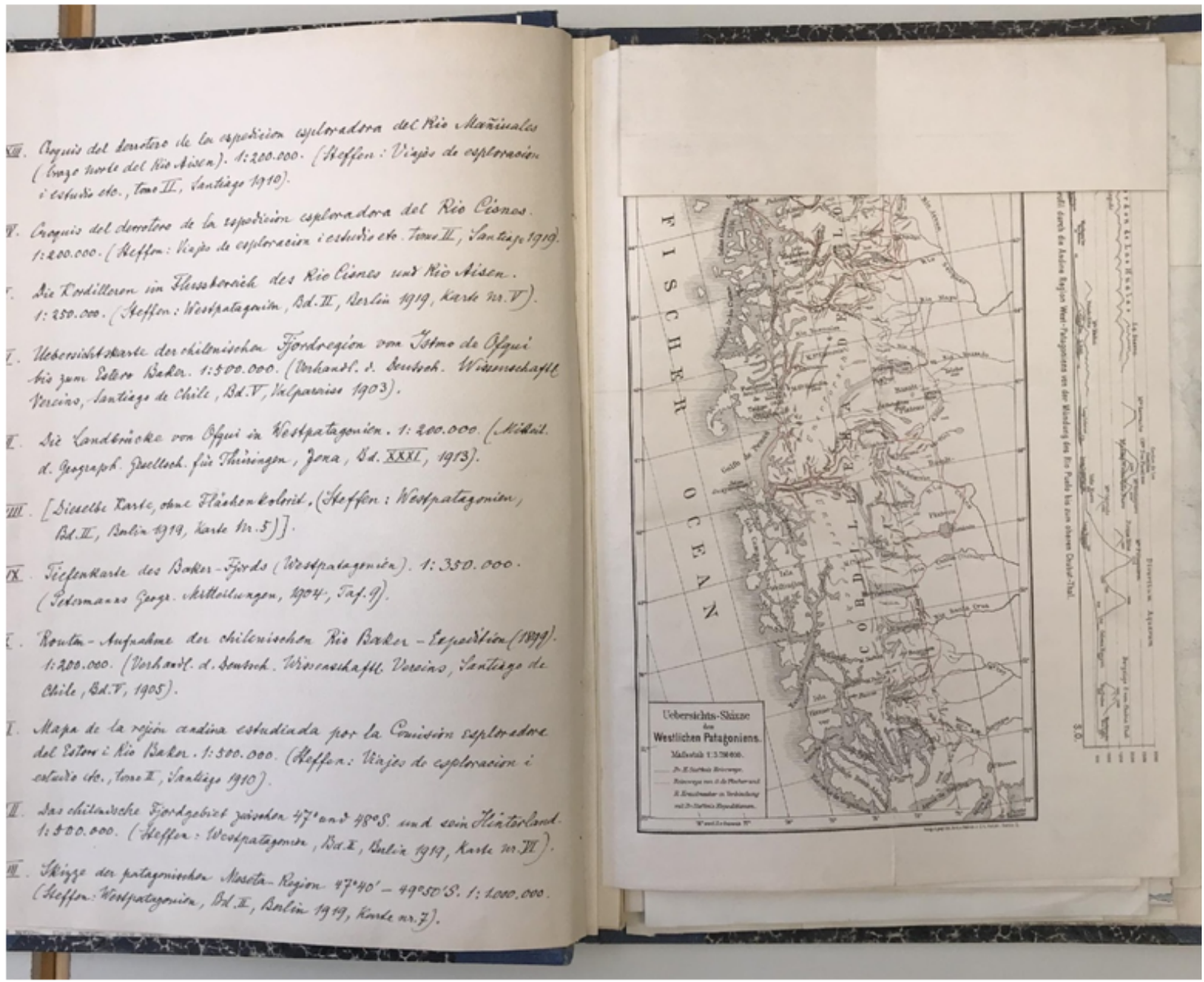

El atlas personal de Hans Steffen: en un cuaderno en blanco ordenó sus notas manuscritas y pegó 33 mapas relativos a las expediciones de las zonas exploradas que había coleccionado para su consulta personal. Inédito. S/f.

Fuente: Foto propia tomada en la Biblioteca del Leibniz-Institut für Länderkunde, Liezpieg Universität. Fondo Hans Steffen.

El trabajo y los textos de Hans Steffen, más allá de ser fundamentales para estudiar el conflicto fronterizo chileno-argentino, también sirven como pistas para examinar la transferencia transatlántica de conocimiento en la coyuntura de cambio de siglo, así como en las relaciones de comunicación, cooperación y rivalidades de los científicos contemporáneos (Latour, 1987). Como interlocutor privilegiado de la Sociedad Geográfica de Berlín, las tareas de Steffen fueron tan variadas y numerosas que en este artículo me limitaré solamente a un aspecto relacionado con las cuestiones aquí tratadas: la contribución de Hans Steffen a la red de científicos que ponían en circulación información, noticias, experiencias, fotografías y materiales diversos; en particular, sobre la geografía patagónica y la comunidad de científicos alemanes.

La correspondencia entre Fritz Reichert y Hans Steffen es una muestra de esto. Reichert nació en Schwäbisch Hall (Alemania) en 1878. En 1898 comenzó sus estudios de química en la Universidad de Estrasburgo (Alsacia, en aquel entonces parte de Alemania) y se graduó en 1902. Recomendado por Dr. Rodolfo Hauthal (un geólogo alemán que residía en la Argentina y que había sido comisionado por el gobierno argentino para contratar un químico con conocimiento en minas y geología), Reichert llegó a Buenos Aires en 1904, justo cuando Steffen regresaba a Europa. Es decir, nunca se encontró personalmente con Steffen.

En la Argentina, Reichert estuvo en contacto con muchos viejos conocidos de Steffen: Francisco Moreno, el Dr. Santiago Roth (suegro de Hauthal, su mentor en Estrasburgo), el ministro de Hacienda Wenceslao 
Escalante, el ministro de Justicia e Instrucción Pública Dr. Carlos Ibarguren, el presidente del Consejo Nacional de Educación Dr. Pedro N. Arata y el banquero Ernesto Tornquist (para quien tenía una carta de presentación de su sobrino Alexander Tornquist, su exprofesor de geología en Estrasburgo). Trabajó en el laboratorio de química del Ministerio de Agricultura, y en 1906 el subsecretario Ibarguren le ofreció el cargo de profesor de química agrícola en el recientemente fundado Instituto Superior de Agronomía y Veterinaria (que luego sería la Facultad de Agronomía y Veterinaria). Al igual que Steffen, mientras durante el año académico Reichert desarrollaba sus tareas en la facultad, durante las vacaciones se dedicaba a su actividad favorita, el alpinismo. Para él no fue solamente un deporte, sino una seria y científica exploración geográfica de lugares aún desconocidos en su época. En consonancia con dicha orientación, fue socio fundador de la Sociedad Argentina de Estudios Geográficos (GAEA). Particularmente se interesó por los Andes patagónicos y la exploración de los hielos continentales patagónicos. Los resultados de sus expediciones patagónicas le sirvieron para publicar, en colaboración con Franz Khun ${ }^{26}$ y Alfred Kölliker, el libro Patagonia (Kölliker y Khun, 1917).

La opinión de Stteffen sobre los asuntos patagónicos siguió siendo una referencia de autoridad tanto para argentinos como para chilenos, aun cuando ya estaba afincado en Europa. En ocasión de una expedición argentina al Canal Baker, tan familiar para Steffen, el Dr. Reichert, quien ya trabajaba en Facultad de Agronomía Villa Ortúzar de la Universidad de Buenos Aires, le escribió desde Santiago en 1913 para pedirle consejos:

Desde Buenos Aires, se realizará una gran expedición al Canal Baker y desde allí a unos 51 grados a principios del próximo verano. El plan general es comenzar desde Puerto Montt en barco, avanzar hasta el fiordo y, desde puntos adecuados, cruzar el hielo hasta el lado del mar argentino. Como estoy familiarizado con los diarios de viaje que publicaste en los Anales de la Universidad de Chile, pensé en contactarte con la esperanza de que me pudieras dar valiosos consejos (Reichert, 1913).

A juzgar por la siguiente carta de Reichert, Steffen le respondió generosamente, no solo le expresó su gratitud a Steffen sino que también comentó que la comisión argentina se manifestaba a favor de una expedición que incluyera tanto personal chileno como argentino. ${ }^{27}$

Tal como ha reseñado el historiador José Pozo Ruiz, Steffen publicó una larga serie de contribuciones en la revista Anales de la Universidad de Chile: "El Istmo de Ofqui en la Patagonia Occidental"; "Contribución a la historia del descubrimiento y la exploración de las cordilleras sudamericanas"; "La cuestión de límites chileno - argentina con especial consideración de la Patagonia"; "Los cerros de las islas de los canales occidentales de la Patagonia, iforman parte de la cordillera de los Andes?; "Recuerdos del Tribunal de Londres" (Pozo Ruiz, 2005, p. 121). Además publicó varios artículos en prestigiosas publicaciones alemanas, como Verhandlungen des Deutschen Wissenschaftlichen Vereins zu Santiago de Chile en la revista de la Sociedad Científica Alemana y otros trabajos cartográficos de la expedición, y en "Noticias petrográficas de Llanquihue" (texto que contiene un resumen de este viaje). Al elegir una audiencia académica, Steffen buscaba la legitimidad de sus proposiciones, desmarcarse de la arena de la política y quedar fuera de la diplomacia; prefería hacer pasar sus reportes como textos estrictamente científicos.

\section{Notas finales}

En sus inicios, los temas de interés de Hans Steffen estaban predominantemente vinculados con la geografía histórica, como se advierte en el temario de sus ya citadas primeras publicaciones. Pero pronto aparecieron otros trabajos muy comprometidos con su interés por Chile. En sus textos, el profesor Steffen destacaba la importancia de las exploraciones y del trabajo campo para realizar las descripciones geográficas. Steffen, más que un teórico de la geografía o un hombre de gabinete, era un explorador, que, a su vez, trabajaba de profesor.

Su recorrido intelectual estuvo definitivamente atravesado por su compromiso político de apoyo a la postura chilena ante el conflicto limítrofe entre Chile y la Argentina por el trazado de la línea en los Andes 
australes a fines del siglo XIX. Al principio, quiso sostener la postura chilena afirmando que existían una Patagonia chilena y otra argentina; Steffen tuvo que ir desestimando los argumentos regionalistas que había sostenido en los inicios de su trabajo, aprendidos de su maestro, el naturalista alemán Alfred Kirchhoof, y comenzó a apelar a su otro mentor intelectual: Ferdinand von Richthofen, de formación en geomorfología. El énfasis que ponía Richthofen en el trabajo de campo le sirvió a Steffen para organizar sus expediciones, utilizar instrumentos, llevar un diario con las mediciones y seguir protocolos científicos de observación sobre los que apoyaba la reivindicación diplomática chilena. Curiosamente, todas las expediciones de Steffen y su equipo arrojaban resultados que probaban empíricamente el principio jurídico abstracto que enarbolaba Chile.

Finalmente, sus últimos escritos ya se centraban casi únicamente cuestiones geográficas asociadas a la política, específicamente su experiencia sobre las cuestiones de límites patagónicos. ${ }^{28}$ Pero, en lo que respecta a su trabajo geográfico, terminó volviendo a una definición geomorfológica de la región: la Patagonia se dividía entre una región montañosa (occidental) y una de mesetas (oriental). Esta diferenciación permitía explicar otros factores geográficos tales como el clima (húmedo versus seco) o la vegetación (selva versus estepa). Esta división de la Patagonia, en realidad, no coincidía con ninguna de las tesis que entonces defendían los gobiernos de ambos países, centradas más bien en la existencia de ríos y altas cumbres cordilleranas.

Después de este recorrido por las ideas, las teorías y las prácticas geográficas desarrolladas por Steffen para la conceptualización y la demarcación de la frontera entre Argentina y Chile queda un interrogante abierto: tras bambalinas, la aparente sólida argumentación científica tenía sus fisuras. Solo para mencionar una, que involucró al propio Steffen, vale la pena traer a colación que el 7 de marzo de 1900, Domingo Gana le escribió una carta reservada a Steffen en la que le consultaba sobre la factibilidad del criterio geográfico cordillerano como medio de delimitación. Expresamente le preguntó si los cerros o picos nevados que se encuentran sobre las islas o cerca de los canales occidentales de la Patagonia deben o no ser considerados como parte de la Cordillera de los Andes (Gana, 1900). No conocemos la respuesta de Steffen, pero, sin duda, él tenía plena conciencia de lo tendencioso de sus prácticas, y, de hecho, es lo que le reprochaba con justa razón a los argentinos. Entonces, es probable que, sabiendo que incluso cuando Argentina, Chile e incluso Gran Bretaña habían usado protocolos científicos, primaron las divergencias (no solo debido a los intereses cruzados, sino también a la falta de certezas). Hans Steffen sabía que la respuesta dependería de aquello que previamente hubiera decidido sostener.

\section{Agradecimientos}

Este trabajo fue realizado en el marco del proyecto CSO2015-65301-P (MINECO/ FEDER). Debo agradecer la beca de investigación otorgada por el Ibero-Amerikanisches Institut (Berlín), que hizo posible el trabajo de archivo; y también la beca Georg Forster Research Fellowship for Experienced Researchers (Fundación Alexander von Humboldt), que me dio la oportunidad de hacer una estancia de investigación en el Hermann von Helmholtz-Zentrum fr Kulturtechnik (Alexander von Humboldt Universititzu Berlín) durante la cual fue escrito este texto.

\section{REFERENCIAS}

A.A. (1900). Argentine-Chilian Boundary. Printed for the Government of the Argentine Republic by William Clowes and Sons, Limited. Stamford Street and Charing Cross.

Ahumada, P. (2014). Paisaje y nación: la majestuosa montaña en el imaginario del siglo XIX. En A. Peliowski y C. Valdés (Eds.), Una geografía imaginada. Diez ensayos sobre arte y naturaleza. Santiago: Ediciones Universidad Alberto Hurtado- Ediciones Metales Pesados.

Anderson, B. (1991). Comunidades imaginadas. Reflexiones sobre el origen y la difusión del nacionalismo. México: Fondo de Cultura Económica. 
Bennet, T. (1995). The formation of the museum. En The Birth of the Museum. History, Theory, Politics (pp. 17-58). Londres y Nueva York: Routledge.

Donoso, R. (1936). El Dr. Hans Steffen. Anales de la Universidad de Chile, 22-23, 4-18. https://10.5354/0717-88 83.2012.24461

Donoso, R. (1937). El Dr. Hans Steffen. En Universidad de Chile (Ed.), Homenaje a la memoria del Dr. Hans Steffen (pp. 5-18). Santiago: Prensas de la Universidad de Chile.

Drago, L. M. (1903). Dictamen de la Comisión arbitral, 1902. Traducido al español por Luis María Drago. https://w ww.dipublico.org/3767/laudo-arbitral-de-su-majestad-britanica-eduardo-vii-1902/.

Farro, M. (2009). La formación del Museo de La Plata. Rosario: Prohistoria Ediciones.

Galdames, L. (1936). Steffen, Profesor. Anales de la Universidad de Chile, 5 (22-23), 19-21. https://10.5354/07178883.2012.24463

Gana, D. (1900). Correspondencia personal de Hans Steffen. Biblioteca del Leibniz-Institut für Länderkunde, Liezpieg Universität. Fondo Hans Steffen.

Gerdes, T., \& Schmidt, S. (2016). Hans Steffen (1865-1936): Grenzerfahrungen eines deutschen Geografen in Chile. Berlin: Ibero-Amerikanisches Institut. Recuperado de https://www.iai.spk-berlin.de/fileadmin/ dokumentenbibliothek/Ibero Bibliographien/Ibero_Bibliographien_10.pdf

Holdich, H. (1899). "The use of practical Geography illustrated by recent frontiers operation". The Geographical Journal 13 (5), 465-480.

Holdich, H. (1891) Proceedings. Royal Geographical Society 13(10), 596-607).

Kölliker, A.; Kühn, F y Reichert, F. (1917). Patagonia; resultados de las expediciones realizadas de 1910 a 1916. Buenos Aires: Sociedad Científica Alemana, 2 t. con 431 p.

Jones, S. B. (1959). Boundary Concepts in the Setting of Place and Time. Annals of the Association of American Geographers, 49(3), 241 - 255. Recuperado de https://www.jstor.org/stable/2561458

Lacoste, P. (2003). La percepción de los límites entre la Argentina y Chile. En La imagen del otro en las relaciones de la Argentina y Chile (1534-2000) (pp. 197-216). Buenos Aires: Fondo de Cultura Económica.

Latour, B. (1987). Science in action: how to follow scientists and engineers through society. Cambridge: Harvard University Press.

Lois, C. (2011). Las evidencias, lo evidente y lo visible: el uso de dispositivos visuales en la argumentación diplomática argentina sobre la Cordillera de los Andes como frontera natural. Treballs de la Societat Catalana de Geografia, 70,7-29. Recuperado de https://www.raco.cat/index.php/TreballsSCGeografia/article/download/68948/32 9131

Lois, C. (2014). Mapas para la nación. Episodios en la Historia de la cartografía argentina. Buenos Aires: Biblos.

Martinic, M. (1981). Los alemanes en la Patagonia Chilena. Anales del Instituto de la Patagonia, 12, 315-316. Recuperado de http://www.bibliotecanacionaldigital.gob.cl/bnd/628/w3-article-287607.html

Martinic, M. (2005). "Los alemanes en la Patagonia Chilena", Punta Arenas. Universidad de Magallanes, Archivo Emilio Held Winkler, Deutsch-Chilenischer Bund, 2005

Moreno, F.P (1898). Meetings of the Royal Geographical Society, session 1898-1899: (p 219-220)

Núñez, A., Arenas, F., y Sabatini, F. (2013). Producción de fronteras e imaginarios geográficos: de la nacionalización a la globalización de la Cordillera de los Andes. En A. Núñez, R. Sánchez y F. Arenas (Eds.), Fronteras en movimiento e imaginarios geográficos; La Cordillera de Los Andes como Espacialidad Sociocultural (pp. 111 - 136). Santiago: GEOlibros \& RIL Editores.

Pozo Ruiz, J. M. (2005). Hans Steffen: Maestro, Geógrafo y Pionero de la Patagonia Occidental. Revista Universum, 20(1), 112 - 123. Recuperado de https://scielo.conicyt.cl/scielo.php?script=sci_arttext\&pid=S0718-2376200 5000100008

Raffestin, C. (1980). Pour une géographie du pouvoir. París: Libraires Techniques (LITEC), Colección Géographie Economique et Sociale. 
Ratzel, F. (1897). Géographie politique. Lausanne/ Geneve: Editions Régionales Européenes [1988]. (Traducción de Pierre Rusch, sous la direction scientifique de Charles Hussy).

Reichert, F. (1913). Carta firmada por Reichert, Santiago, 30 April 1913. En, Universidad de Buenos Aires /Facultad de Agronomía Villa Ortúzar. Biblioteca del Leibniz-Institut für Länderkunde, Liezpieg Universität. Fondo Steffen.

Richthofen, F. (1886). Führer Für Forschungsreisen. - Cap.XVI, 3. Berlin; Verlag Robert Oppenheim

Said, E. (1978). Orientalismo. Madrid: Debate.

Sanhueza Cerda, C. (2012). El objetivo del Instituto Pedagógico no es el de formar geógrafos. Hans Steffen y la transferencia del saber geográfico alemán a Chile. 1893-1907. Historia, 45, $171-197$

Sanhueza Cerda, C. (2014). Un saber geográfico en acción: práctica disciplinaria de Hans Steffen en Chile (1889-1913). Magallania, 40(1), 21 - 44.

Schlögel, K. (2003). En el espacio leemos el tiempo. Sobre Historia de la civilización y Geopolitica. Madrid: Siruela, [2007]. p. 233. (Trad. Im Raume lesen wir die Zeit. Úber Zivilisationsgeschichte und Geopolitik, Múnich-Viena, Carl Hanser Verlag)

Steffen, Hans (1892). "La polémica sobre la autenticidad de la biografía más antigua de Colón." Anales de la Universidad de Chile, pp. 119-150.

Steffen, H. (20 de marzo de 1900). Cartas de Hans Steffen a Scott Keltie. [Legados Hans Steffen, Instituto Iberoamericano de Berlín; caja E 4.]

Steffen, H. (1931 [ms 1930]). "La línea divisoria de las aguas como elemento fisiográfico y principio de demarcación de limites". IAI. Copia mecanografiada anotada y corregida por el propio Steffen. IAI. Tiene una nota de puño y letra en la primera página "Copia del ms remitido al Director de la Rev. de Hist. y Geogr. a principios de marzo de 1930).

Steffen, H. (1928). El supuesto primer descubrimiento de la cordillera patagónica desde el lado atlántico. Santiago: Imprenta Cervantes.

Vega, A. (1642). Los Andes y el territorio de Chile en el siglo XVI. Descripción, reconocimiento e invención. Santiago: Dibam.

Williams, F. (2010). Entre el desierto y el jardin. Buenos Aires: Prometeo.

\section{Notas}

1 Véase Pozo Ruiz, 2005.

2 Sobre la fundación del magisterio en la Argentina, véase Núñez-Pérez, 2010.

3 Domingo Gana Cruz (1845 - 1910) fue un diputado chileno que en 1882 comenzó su carrera como diplomático. Fue ministro plenipotenciario en México (hasta 1884), en Brasil (1885), en Washington D.C. (1885-1888), en Berlín y Roma (1888-1892) y en España (1898). De regreso a Chile, se hizo cargo de las comisiones de límites con Argentina (1893-1894).

4 Los datos biográficos están basados en Sagredo, 2016; Sanhueza Cerda, 2012; Pozo Ruiz, 2005; Thomas Gerdes y Stefan Schmidt, 2016. Teniendo en cuenta que no todos ellos coinciden entre sí, he optado por aquella información que resulta más sólida según los documentos consultados por los autores citados.

5 En el contexto del auge del género "enciclopedia" del siglo XVIII, los eruditos Renatus Gotthelf Löbel (1767-1799) y Christian Wilhelm Franke (1765-1831) iniciaron el ambicioso proyecto Conversations- Lexikon, que comenzó a publicarse en 1796 en Leipzig. Entre las innovaciones de esta etapa de la Enciclopedia es que, además de la agenda tradicional centrada en mitología, filosofía e historia natural, se incorporaron temas nuevos, entre ellos, geografía, historia y bibliografía. Cuando Löebel murió, la firma tuvo un giro radical debido a la incorporación de un socio que sería clave en la continuidad de esta publicación: Friedrich Brockhous (1772-1823). En 1808 Brockhous compró el copyright de la obra. Durante el siglo XIX se publicaron trece ediciones, algo que puede dar la pauta sobre lo influente que fue esta obra en su época. A tal punto fue crucial la dirección de Brockhous, que el nombre original Konversationslexikon or Allgemeine deutsche Real-Encyklopädie für die gebildeten Stände(General German Encyclopedia for the Educated), hacia fines del siglo XIX incluyó el nombre Brockhaus en el título y llegó a ser conocida simplemente como Brockhaus Enzyklopädie o Der grosse Brockhous. Véase Chisholm, Hugh, ed. (1911). "Encyclopaedia". Encyclopædia Britannica, 9 (11th ed.). Cambridge University Press. pp. 381-382. 
6 En cierta manera, este texto puede ser entendido como la continuación de un artículo que he publicado anteriormente, en el que analizo las mismas cuestiones aquí planteadas pero enfocadas desde la perspectiva de la posición Argentina ante este mismo dilema. Véase Lois, 2011.

7 En tanto el principio de utis possidetis recalaba en antecedentes históricos, la revisión y la interpretación de documentos antiguos era de vital importancia.

8 El título completo es Argentine-Chilian Boundary. Report presented to the Tribunal appointed by her Britannic Majesty's 'to consider and report upon the differences which have arisen with regard to the frontier between the Argentine and Chilian (sic) Republics" to justify the Argentine claims for the Boundary in the summit of the Cordillera de Los Andes, according to the Treaties of 1881 \& 1893". Printed in compliance with the request of the Tribunal, dated December 21, 1899. London. Printed for the Government of the Argentine Republic by William Clowes and Sons, Limited. Stamford Street and Charing Cross. 1900. Dos años más se publicó una versión londinense en español, en dos volúmenes: Frontera argentino-chilena. Memoria presentada al Tribunal nombrado por el gobierno de Su Majestad británica "para considerar e informar sobre las diferencias suscitadas respecto a la frontera entre las Repúblicas Argentina y Chilena" a fin de justificar la demanda argentina de que el límite se trace en la cumbre de la cordillera de los Andes de acuerdo con los tratados de 1881 y 1893. Impresa para satisfacer la indicación hecha por el Tribunal en diciembre 21 de 1899. Londres, Impresa para el gobierno de la República Argentina por W. Clowes e hijos, 1902.

9 Sobre los problemas metodológicos que tuvo la diplomacia para recurrir a esos documentos como forma de legitimar sus pretensiones, véase, Lacoste (2003), especialmente, 32-33. Para un análisis de los registros gráficos de la Cordillera, puede consultarse Ahumada (2014) y Vega (2016, especialmente 197-208). Sobre la relación entre fronteras, la cordillera andina y los imaginarios geográficos, véase Núñez, Arenas y Sabatini (2013, pp. 111-136).

10 Me refiero a las "geografías imaginarias" en los términos que Edward Said utilizó en su libro Orientalismo: "La práctica universal de establecer en la mente un espacio familiar que es 'nuestro' y un espacio no familiar que es el 'suyo' es una manera de hacer distinciones que pueden ser totalmente arbitrarias. Utilizo la palabra 'arbitrario' porque la geografía imaginaria que distingue entre 'nuestro territorio y el territorio de los bárbaros' no requiere que los bárbaros reconozcan esta distinción” (Said, 1978, p. 87).

11 La frontera solía ser una zona, un espacio articulado por puestos avanzados, fortificaciones principales y secundarias, y calzadas de retaguardia para casos de frontera. En cualquier caso, hay que remarcar que esta tendencia hacia la linealidad no implicó necesariamente la desaparición de ciertas prácticas de frontera más compatibles con la noción medieval de frontera-zona o lugar híbrido sin límites netos (y que incluso la demarcación estricta de esos límites en el terreno tampoco se tradujo en todos los casos en una diferenciación cultural o social concreta. Por otra parte, este imperativo de límites lineales internacionales no era del todo novedoso: salvando las diferencias históricas y conceptuales, puede pensarse que el trazado de la línea de Tordesillas en 1494 para dividir los territorios lusitanos e hispánicos de ultramar puede ser un preludio de la línea pensada como dispositivo de demarcación territorial -aunque en ese caso se trató de una empresa cartográfica, imposible de demarcar en el terreno-.

12 El propio Ratzel da una serie de contraejemplos en los que la "frontera montañosa" no divide dominios naturales o no se ajusta al principio expuesto, pero eso no impugna los presupuestos generales.

13 El Coronel Sir Thomas Hungerford Holdich (1843-1929) fue un geógrafo inglés que alcanzó a desempeñarse como presidente de la Royal Geographical Society. Además, fue superintendente de Frontier Surveys en la India Británica.

14 Francisco Pascasio Moreno (1852-1919) fue un naturalista argentino que, desde muy joven, se dedicó a la exploración y al coleccionismo de fósiles. Su intensa trayectoria como explorador de la Patagonia le valió un lugar destacado en las comisiones y las delegaciones argentinas que participaron en las negociaciones con Chile y ante terceros. Participó en la elaboración de diversas obras sobre el mismo tema (aunque en muchas de ellas no figura su nombre, como era habitual en los documentos diplomáticos de este tipo). Algunos de esos trabajos son: Records of the proceedings of the Argentine and Chilian experts concerning the demarcation of the boundary-line between the Argentine Republic and Chili (en colaboración con Diego Barros Arana), Buenos Aires: M. Biedma é hijo, 1898. Reconnaissance de la région Andine de la République Argentine. Notes préliminaires sur une excursion aux territoires du Neuquén, Rio Negro, Chubut et Santa Cruz, effectuée par les sections topographique et géologique. 1897. La Plata: Museo de La Plata.

15 "La línea divisoria de las aguas como elemento fisiográfico y principio de demarcación de límites". IAI. Consulté la copia mecanografiada anotada y corregida por el propio Steffen (documento inédito). IAI. Tiene una nota de puño y letra en la primera página "Copia del ms. remitido al Director de la Revistar de Historia y Geografía a principios de marzo de 1930) al que me referiré como "Steffen Hans (1931)"

16 Para este trabajo me he basado en una copia mecanografiada del original datada en 1931.

17 Entre ellos, Eduard Poeppig, quien en su gran obra intitulada "Viaje en Chile, en el Perú i en el río Amazonas, durante los años de 1827 a 1832" registra descripciones geográficas de la naturaleza de Chile y de sus relaciones mutuas con los habitantes y observaciones de carácter geomorfológico de alto valor científico. Otro alemán que inspiró a Steffen fue Rodulfo Amando Philippi, de quien escribió: "El primer viaje de estudio que emprendió el Dr. Philippi en Chile, acompañado por sus amigos Döll i Ochsenius, se dirigió en febrero de 1852, al volcán Osorno, que fue ascendido, según 
la relación de Philippi, hasta 400 pies debajo de la cima..." [Steffen, H. (1910). Contribución de los alemanes al estudio de la geografía y geología de Chile durante el primer siglo de independencia. En Los alemanes en Chile (p. 202). Imprenta Universitaria.] Más adelante se refiere a la labor de Philippi como director del Museo Nacional, y a la exploración de este último de Atacama y a su subsecuente obra: Viaje al desierto de Atacama (Pozo Ruiz, 2005, p. 119).

18 Véase Bennet, 1995 (especialmente, el capítulo 1: "The formation of the museum” (17-58)). Para una visión general sobre el museo y el nacionalismo, hay que remitir al clásico trabajo de Benedict Anderson (en particular al capítulo "El censo, el mapa y el museo" agregado a la edición de 1991). Farro, M. La formación del Museo de La Plata, Prohistoria Ediciones, Rosario, 2009.

19 Tanto Ricardo Donoso como Luis Galdames fueron alumnos de Steffen en el Instituto Pedagógico. Ambos escribieron sobre Hans Steffen en la Revista Anales de la Universidad de Chile del tercer trimestre de 1936, pp. 5- 21.

20 Y para entonces existía un importante asentamiento de los colonos galeses en el alto valle del río Chubut (Williams, 2010), así como otras colonias -entre ellas, Trevelín -que funcionaban como enclaves en el "desierto"-.

21 Sobre el documento en torno al cual se organizó el argumento argentino presentado ante el Laudo, véase Lois, 2011.

22 En ese caso, más bien me refería a fotos: a la inscripción manuscrita sobre la fotografía de datos tales como nombres de accidentes geográficos, altitudes o puntos cardinales. Salvando las diferencias, me interesa establecer la conexión entre ambas prácticas.

23 El ingeniero y geógrafo chileno Alejandro Bertrand Huillard (1854-1942) se incorporó al Instituto Nacional en 1868, estudió matemáticas y luego Ingeniería en la Universidad de Chile -y finalmente se recibió como ingeniero geográfico, ingeniero civil e ingeniero en minas en 1878-. Fue nombrado profesor de dibujo lineal en el Instituto Nacional y jefe de la Sección de Planos de la Oficina de Hidrográfica, en donde elaboró informes y mapas de Tacna, Arica y Tarapacá y trazó los límites fronterizos de Chile. Fue ingeniero primero de la Comisión de Límites, y, con ese cargo, fue comisionado por el gobierno para especializarse en Europa en planos topográficos. Cuando regresó, en 1895, ocupó el Ministerio de Obras Públicas. En 1898, durante el Gobierno de Federico Errázurriz, fue llamado a asesorar a la legación chilena ante el gobierno británico a raíz de los litigios fronterizos entre Argentina, Bolivia y Perú.

$24 \mathrm{La}$ intención persuasiva de los informes argentino y chileno no está limitada a su intención explícita de influir sobre la opinión del árbitro, sino que incluye una serie de estrategias de puesta en circulación de esta obra en ámbitos más amplios. Por ejemplo, el ejemplar consultado para esta investigación fue un obsequio del Gobierno argentino a la American Geographical Society, entregado el 12 de diciembre de 1901, es decir, casi en simultáneo con la publicación de la obra y antes de la resolución del litigio.

25 Entrevista personal con el profesor Worlf Staub, especialista en Hans Steffen en la Universidad de Hamburgo.

26 Franz Kuhn también publicó, en 1922, Fundamentos de fisiografía argentina (Buenos Aires: Biblioteca del Oficial del Círculo Militar Argentino).

27 "Me gustaría expresar mi sincero agradecimiento por sus importantes consejos y por el interés que ha demostrado en la expedición planificada. (...) La expedición se financiará en parte con fondos privados y en parte con fondos del gobierno. El botánico Prof. Dr. Hicken de la universidad local [Santiago de Chile] dice que los argentinos han tomado el interés de los círculos del gobierno local de la manera más agradecida. El Dr. Hicken, a quien le entregué su carta, probablemente llegará a Santiago estos días para investigar cómo lograr que el gobierno chileno participe. No hay nada que nos impida tener personalidad chilena en la expedición.” Fecha: Buenos Aires 16. Mai 1913. Biblioteca del Leibniz-Institut für Länderkunde, Liezpieg Universität. Fondo Steffen.

28 La cuestión de límites chileno argentina con especial consideración de la Patagonia" (Anales de la Universidad de Chile, 94(22-23), 1936, 187-231); "Los cerros de las islas de los canales occidentales de la Patagonia, ¿forman parte de la Cordillera de los Andes?” Anales de la Universidad de Chile, Vol. 94, N²2-23, 1936, pp. 232-241) y "Recuerdos del Tribunal Arbitral en Londres”. Anales de la Universidad de Chile, Vol. 94, N²2-23, 1936, pp. 242-256; entre otros. 